\title{
For a Better Dictionary: Revisiting Ecolexicography as a New Paradigm
}

\author{
Xiqin Liu, School of Foreign Languages / Research Center for \\ Indian Ocean Island Countries, South China University of Technology, \\ Guangzhou, China (flxqliu@scut.edu.cn) \\ Jing Lyu, School of Foreign Languages, South China \\ Agricultural University, Guangzhou, China \\ (Corresponding Author, jinglyu@qq.com) \\ and \\ Dongping Zheng, Department of Second Language Studies, \\ University of Hawai'i at Mānoa, Honolulu, USA (zhengd@hawaii.edu)
}

\begin{abstract}
Driven by practical conundrums that users often face in maximizing (e-)dictionaries as a companion resource, this article revisits and redefines ecolexicography as a new paradigm that situates compilers and users in a relational dynamic. Drawing insights from ecolinguistics and cognitive studies, it appeals for rethinking the compiler-user relationship and placing dictionaries in a distributed cognitive system. A multidimensional framework of ecolexicography is proposed, consisting of a micro-level and a macro-level. To the micro-level, both symbolic and cognitive dimensions are added: (1) the dictionary can be symbolically viewed as a semantic and semiotic ecology; (2) dialogicality should be highlighted as an essential aspect of e-dictionary compilation/ design, and distributed cognition can be emancipatory for rethinking dictionary use. The macrolevel concerns the obligations of lexicographers as committed to three interrelated ecologies or ecosystems: language, socio-culture and nature. Transdisciplinary in nature, ecolexicography involves a holistic, systematic and integrative methodology to nourish lexicographical practice and research. Corpus-based Frame Analysis is introduced to identify ecologically destructive frames and ideologies so that the dictionary discourse could be reframed. The study upgrades our understanding of the ontological, epistemological and methodological aspects related to ecolexicography, serving as a call for philosophical reflections on metalexicography. It is also expected to create an opportunity for lexicographers to examine problems with (e-)dictionaries in a new light and dialogue about how to find solutions.
\end{abstract}

Keywords: E-DICTIONARY, LEARNER'S DICTIONARY, SEMANTIC ECOLOGY, SEMIOTIC ECOLOGY, ECOLINGUISTICS, ECOLEXICOGRAPHY, DIALOGICALITY, DISTRIBUTED COGNITION, SOCIO-CULTURE, CORPUS-BASED FRAME ANALYSIS, METALEXICOGRAPHY

Opsomming: Vir 'n verbeterde woordeboek: 'n Herbesoek aan die ekoleksikografie as nuwe paradigma. Voortgedryf deur praktiese probleme wat gebruikers dikwels ervaar in die maksimalisering van (e-)woordeboeke as 'n handboekhulpbron, word 'n herbesoek 
aan die ekoleksikografie gebring en word dit geherdefinieer as nuwe paradigma wat samestellers en gebruikers in 'n relasionele dinamika posisioneer. Uit insigte wat verkry is uit die ekolinguistiek en kognitiewe studies word daar gevra om ' $n$ herbesinning van die samesteller-gebruikers-verhouding en om woordeboeke in 'n verspreide kognitiewe stelsel te beskou. 'n Multidimensionele raamwerk van die ekoleksikografie, wat bestaan uit 'n mikro- en makrovlak, word voorgestel. Tot die mikrovlak word beide simboliese en kognitiewe dimensies gevoeg: (1) die woordeboek kan simbolies beskou word as semantiese en semiotiese ekologie; (2) diskoers moet beklemtoon word as 'n essensiële aspek van die samestelling/ontwerp van die e-woordeboek, en verspreide kognisie kan bevrydend wees vir die herbeskouing van woordeboekgebruik. Die makrovlak is gemoeid met die verpligting van leksikograwe wat verbind is tot drie ekologieë of ekostelsels wat onderling aan mekaar verbonde is: die taal, sosiokultuur en natuur. Die ekoleksikografie, transdissiplinêr van aard, behels 'n holistiese, sistematiese en integrerende metodologie om die leksikografiese praktyk en navorsing te voed. Korpusgebaseerde Raamanalise word gebruik om ekologies destruktiewe raamwerke en ideologieë te identifiseer sodat woordeboekdiskoers geherdefinieer kan word. Hierdie studie verbeter ons begrip van die ontologiese, epistemologiese en metodologiese aspekte wat verband hou met die ekoleksikografie, en ontlok filosofiese denke rakende die metaleksikografie. Daar word ook verwag dat dit 'n geleentheid vir leksikograwe sal bied om probleme rakende (e-)woordeboeke in 'n nuwe lig te ondersoek en vir gesprekvoering oor hoe om oplossings vir hierdie probleme te vind.

Sleutelwoorde: E-WOORDEBOEK, AANLEERDERSWOORDEBOEK, SEMANTIESE EKOLOGIE, SEMIOTIESE EKOLOGIE, EKOLINGUISTIEK, EKOLEKSIKOGRAFIE, DISKOERS, VERSPREIDE KOGNISIE, SOSIOKULTUUR, KORPUSGEBASEERDE RAAMANALISE, METALEKSIKOGRAFIE

\section{Introduction}

Ecology refers to (the scientific study of) the relation of plants and living creatures to each other and to their surroundings. How organisms interact with one another and with their environment has become "a central question governing the survival and sustainability of human societies, cultures and languages" (Cronin 2017). Ecolinguistics (or ecological linguistics) investigates language in an ecological context. It explores the role of language in the human society and the ecosystem, and shows how linguistics can be used to address key ecological issues. This new branch of linguistics represents a turning point in language studies. Revolutionary in nature, it catalyzes the growth of many interdisciplinary fields of research. It distinguishes two positions for the ecological study of languages: one concerned with the relations between languages, and languages with the environment; the other investigating the interrelationships existing in a language (Albuquerque 2018). This distinction was first elaborated by Makkai (1993), who put forward the term "exoecological linguistics" for the former, and "endoecological linguistics" for the latter. They could be understood as the macrolevel and the micro-level in the framework of ecolinguistics. 
Originating from lexicography and ecolinguistics, ecolexicography was first proposed by Sarmento (2000) as a part of applied linguistics, with a focus on addressing the effects and results that each lexeme brings to dictionary users. Sarmento (2005) argues that the main issue of ecolexicography is what the role of words is in our world and how a word can create, maintain or destroy a world. Many scholars (e.g. Hoey 2001; Tsunoda 2005) resonate with this viewpoint, stressing the importance of dictionaries as a tool of promoting linguistic diversity, socio-cultural harmony, and environmental sustainability. However, Sarmento $(2000,2002,2005)$ holds that ecolexicography does not deal with the elaboration of ecology dictionaries or ecological terms. This perspective may be too limited as ecolexicography unavoidably faces the treatment of ecological vocabulary.

Albuquerque (2018) describes ecolexicography as a new discipline in lexicography and explores what it could contribute to pedagogical lexicography, especially in the analysis of dictionaries and the microstructure, and in producing teachers with a different worldview and in environmental education for students. He argues that eco-lexicography as a science should assist lexicographers to: develop a new way of looking at the world (the ecological vision of the world) and the words; realize the power of the words of a language for its speakers and for the world; offer ways to identify the ecological factors in language; and propose a new structure of article and definition (ibid.). He also points out that research on ecolexicography regarding these aspects is only at an embryonic stage, and it is necessary to lay a foundation for the ecolexicography approach that needs more researchers, research and projects. There is actually significant potential for (re)discovering important inroads or beneficial outcomes.

To breathe new life into this field, we have to re-examine the lexicographical products seriously, and rethink the cognitive and socio-cultural processes of dictionary compilation and use from a novel perspective. This article is expected to create an opportunity for lexicographers to dialogue about the problems they encounter with (e-)dictionaries and communicate how our ecolexicography proposal can shed light on the solutions it can provide.

\section{Rationale for revisiting ecolexicography}

\subsection{Practical problems: the necessity}

Abundant literature (e.g. Hoey 2001; Tsunoda 2005) reveals that there are at least two kinds of problems with current dictionaries: anti-ecological language and destructive ideologies, and problematic (e-)dictionary design and use.

\subsubsection{Anti-ecological language and destructive ideologies}

Many dictionaries, including pedagogical dictionaries, are not ecologically ori- 
ented and do not pay enough attention to users' awareness of the importance of environmental protection and sustainable development of human society or cultures (Wang 2003).

Tian et al. (2016) find that some examples in The New Age English-Chinese Dictionary (NAECD) fail to adopt a positive attitude toward ecology. Four tendencies of lexicographers dealing with biological and ecological lexemes were identified by Trampe (2001): (1) reification, i.e. treatment of certain living beings as things (goods of production or consumption), e.g. "cow" is a commodity; (2) use of euphemism (and other language mechanisms) to hide certain facts that may be regarded as violent for the consumer or general public, e.g. "pesticide" is replaced by "plant protection tool"; (3) defamation of traditional/ subsistence agriculture, which are generally labeled as being "unproductive", "expensive", etc.; (4) use of slogans and phraseological elements to convince the population that the destruction of the ecosystem is something natural/inevitable or even to disguise such destruction, affirming it as something good, e.g. "to create more wealth for all". These four tendencies alert lexicographers to the anti-ecological language of the world economic vision that is fragmented, increasingly alienating the human being from other species and nature (Albuquerque 2018).

Furthermore, anti-sociocultural ideologies are found in dictionaries. Tenorio (2000) claims that some definitions in The Collins COBUILD English Language Dictionary (CCELD) are inaccurate and biased in gender representation, and ignore changes in society. Hu et al. (2019) assert that The Contemporary Chinese Dictionary $(C C D)$ portrays men as valuable social members while overlooking the value of women.

We found similar results (see Appendices I and II) after examining three of the "Big Five" dictionaries': Oxford Advanced Learner's Dictionary (OALD9), Longman Dictionary of Contemporary English (LDOCE5) and Collins COBUILD Advanced Learner's Dictionary (COBUILD8). To achieve representativeness and generalizability of our data and the outcomes, we retrieved 30 random pages from each dictionary and all the linguistic data in those pages were collected to create a corpus. Each text was annotated and analyzed to disclose the ecologically (non)destructive frames in dictionaries. Frames (also called schemas) are schematizations of our experience and knowledge of the world (Fillmore 1985), and description of word meanings must be associated with cognitive frames in the reader's mind ${ }^{2}$. In our survey, we adapted and integrated corpus-based discourse analysis (Baker 2006) into frame analysis (Fillmore and Baker 2009; Lakoff 2014). The procedure of frame analysis (Blackmore and Holmes 2013) is to ask the following questions for a particular frame: What values does the frame embody? Is a response necessary? Can the frame be challenged? If so, how? Can (and should) a new frame be created?

We compared the frames represented by the headwords in the dictionaries and those represented by the same words in Corpus of Contemporary American English (COCA). In the end, we identified over 30 potentially destructive 
instances (definitions and examples) from more than 30 entries of each of the three dictionaries. For instance, "He had abused his own daughter" and "The boy had been sexually abused" are used as illustrative examples in the entry of "abuse" in OALD9 (see Part A in Appendix I). In total, we found that 23 themes were disharmoniously framed, and many of them were beyond the traditional lexicographic attention because it seems that the top seven themes we have identified (violence, animal, drug, possession, pollution, sea and alcohol) have not been fully discussed in lexicography (Lyu and Liu, in preparation). Destructive frames and ideologies (e.g. "Children are the target of sexual harassment", see Part A in Appendix II) seem to be prevalent, largely due to lexicographers' choice in this challenging age of the Anthropocene (ibid.).

\subsubsection{Problematic (e-)dictionary design and use}

Researchers find that many lexicographic e-products were developed with little influence from innovative theoretical suggestions and, as a result, current e-dictionaries often do not live up to the expectations of users and are misused by their users (cf. Gouws 2014). Many of them have problems including definition insufficiency and inaccuracy (Zhang 2015: 79-82), lack of customization (Liu, Zheng and Chen 2019), information overload (Gouws and Tarp 2017; Huang and Tarp 2021) and lack of education in dictionary use (e.g. Winestock and Jeong 2014). For instance, dictionaries integrated into English learning applications produced in China were found to suffer from deficiencies such as "inconsistent treatment of words and senses, data overload, difficult access, and inconvenient location of the pop-up window that displays the lexicographical items", which may "impact negatively on the learners' motivation and the learning process in general" (Huang and Tarp 2021). In the digital revolution, the way of displaying data in e-dictionaries must be redefined (Gouws 2014), and semiotic resources (e.g. color, typography, and navigation devices) should be properly employed according to the context (Liu 2015, 2017; Farina et al. 2019).

Underlying reasons for the above problems are complex, and some may be ontological and epistemological. At the fundamental level, many lexicographers, perhaps indulged in Western analytical thinking, still hold a fragmented view, rather than a systematic view of the components in a dictionary and its microstructure. There lacks an awareness that a dictionary, comparable to ecology, is characterized by complexity, holism, diversity and dynamicity. For example, the lack of e-dictionary customization and individualization is against the principle of ecological diversity and dynamicity. The technical transition from paper-based to electronic layout demands different cognitive attention and visual engagement. Users' individual and collective needs should be considered by designers. From an ecological perspective of language learning, even if a universal dictionary could be made, the users would tailor its use (especially those with a high degree of literacy and computer skills). So, dictionary design should try to allow users to adapt the product to their needs, goals and values, 
to some extent (see Liu, Zheng and Chen 2019 for an example of varying types of motivation for smartphone dictionary use in China).

To make things even worse, the practice that one definition/example fits all, or lack of adaptability, may aggravate the problem of data overload. For instance, the word "pig" is defined as "An omnivorous domesticated hoofed mammal with sparse bristly hair and a flat snout for rooting in the soil, kept for its meat" in the Lexico.com (called Oxford Dictionaries English before 2019, https://www.lexico.com/definition/pig). This is a general dictionary (rather than a specialized one) and the definition is offered to users in general, but this is a very difficult technical definition. It is very likely that many users do not understand the difficult terminologies in the complicated explanation. Perhaps such information/data overload (Gouws and Tarp 2017), traceable to inconsideration of dictionary types and users, is against the principle of "ecological harmony" (cf. Zhou 2017). The idea that online dictionaries have unlimited space has furthered the often uncritical inclusion of too much data (Gouws and Tarp 2017).

In brief, the status quo highlights the importance of proper ontological and epistemological orientations for lexicography. With an ecological view, ecolexicography has the potential to offer a fresh set of theoretical-methodological contributions in dictionary research and compilation, especially in the proposal of a differentiated microstructure (Albuquerque 2018). Nevertheless, for systematic strategies to remedy the above problems, ecolexicography needs to be redefined as a new paradigm by drawing theoretical and methodological insights from related fields.

\subsection{Theoretical underpinnings: the feasibility}

\subsubsection{Lexicographical theories}

Three theories may shed new light on ecolexicography, the Communicative Theory of Lexicography (Yong and Peng 2007), the Function Theory of Lexicography (Bergenholtz and Nielsen 2006; Tarp 2007), and the Discourse Approach to Critical Lexicography (Chen 2019).

The first two theories are user-oriented and focus on the interactivity feature of dictionary compilation and use. The Communicative Theory of Lexicography views the dictionary as communication (instead of reference and text). Drawing insights from Systemic-Functional Linguistics (Halliday 1985), Yong and Peng (2007) assert that dictionary context encompasses three subcategories: field, mode and tenor. This communicative perspective inspires reconsideration of the interaction between dictionary compilers and users. According to the Function Theory of Lexicography (Bergenholtz and Nielsen 2006; Tarp 2007), dictionary functions are communication-orientated or cognition-orientated, and lexicographers must identify the relevant functions and select and present appropriate data so that the dictionary satisfies the needs of users in different situations. 
Chen's (2019) Discourse Approach to Critical Lexicography, or Critical Lexicographical Discourse Studies (CLDS), offers both theoretical and methodological inspirations for ecolexicography. Responding to the call for lexicographers' social accountability, CLDS views the dictionary as discourse, and discourse is a three-tiered concept consisting of "a piece of text, an instance of discursive practice and an instance of social practice" (Fairclough 1992). To uncover the ideologies and power relations in dictionaries, CLDS analysts will first conduct an analysis of the dictionary as text, investigating, for example, the choice of vocabulary in explaining the meaning of a word, the choice of illustrative examples, and the order of senses (ibid.). Thereafter how the dictionary is produced, distributed and consumed will be examined, followed by a discussion of the social context in which the dictionary is produced and consumed (ibid.).

\subsubsection{Ecolinguistic and cognitive theories}

Two interrelated theoretical achievements in ecolinguistic and cognitive studies may offer nourishments for ecolexicography and help transform the discipline. The first is the "distributed language" and EDD (ecological, dialogical and distributed) theory (Van Lier 2002; Cowley 2011; Linell 2009, 2013; Zheng 2012; Steffensen 2015), and the second is Steffensen and Fill's (2014) redefinition of ecolinguistics by identifying the four ways in which the ecology of language is conceptualized.

Distributed language theory means that language is not an independent symbolic system used by individuals for communication but rather an array of behaviors that constitute human interaction. Language perception occurs in a context of activity and interactivity (Van Lier 2002). Permeating the collective, individual and affective life of living beings, language is a profoundly distributed, multi-centric activity as a part of our ecology, and it gives us an extended ecology in which our co-ordination is saturated by values and norms that are derived from our sociocultural environment (Cowley 2011). In brief, language (or language use) is ecological, dialogical (linked to others) and distributed (rather than located to any single place, such as the speaker's brain) (Zheng 2012).

In applied linguistics, Van Lier (2002) might be the first to have introduced an ecological perspective to language education. The ecological view has inspired a rethink of language and language acquisition/cognition from a sociocultural perspective and boosted the development of such emerging theories as "the Complexity Theory" (see Larsen-Freeman 2011). Ecolinguists redefine language by dividing it into two different consensual domains: (1) first-order languaging (linguistic actions and activities in the communication); (2) secondorder sociocultural inscriptions and norms (Kravchenko 2009). Following this theoretical vein, Zheng (2012) proposed her ecological view of language learning and use which highlights the dialogicality and distributed cognition of participants in communication. Distributed cognition means that cognition is spread in and reliant on different contexts. Traditional cognition is redefined as 
an activity "distributed" in the physical and socio-cultural environment. In cultural ecologies, resources like a dictionary can link people in practices that enable the accomplishment of tasks.

In ecological terms, agents' languaging behaviors are caused not by stimuli but the affordances, opportunities for action and coaction motivated by the ecosocial environments (Zheng et al. 2012). Language is embodied (not merely abstractly procedural), embedded (shaping and shaped by social systems in a cultural world), enacted (living in or realized in and through action), extended, situated, and multi-scalar (existing on different time-scales) (Cowley 2011; Linell 2013).

Based on the communication models of semiotic activity by Zheng (2012) and Linell (2009), we build an ecological model of lexicographical interaction (see Figure 1).

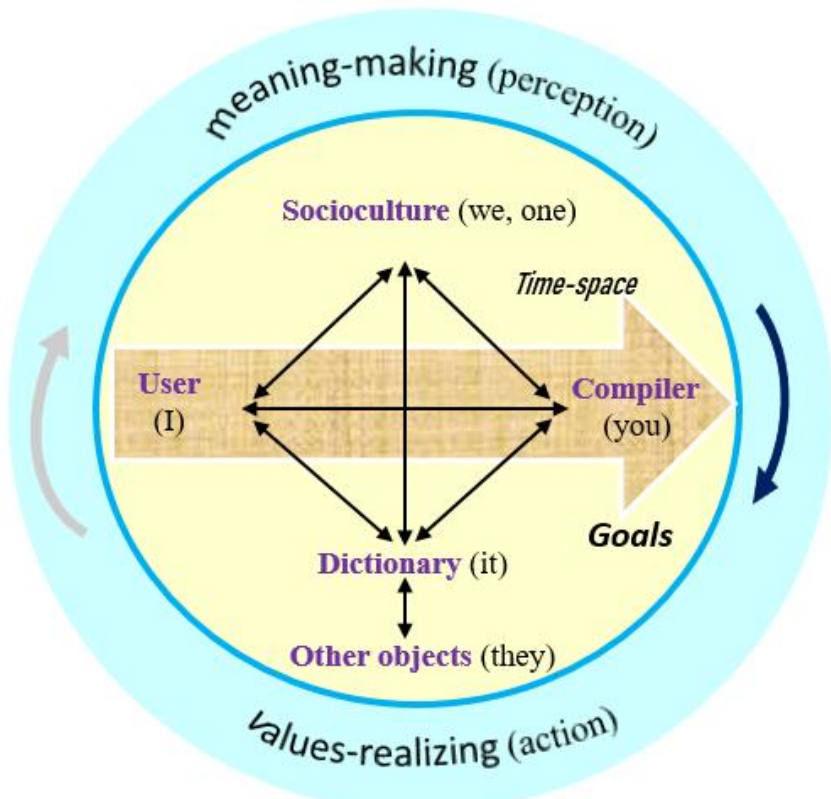

Figure 1: An ecological model of lexicographical interaction: dialogicality and distributed cognition

In the outer layer of the model, there are two concepts from ecological psychology, meaning-making (perception system) and values-realizing (action system). Values-realizing means that an individual agent makes "a conscious choice among multiple values at play in any given moment of action and interaction" (Zheng et al. 2012). It is values that "guide the selection and revision of goals across 
diverse time-space scales, under which the sociocultural norm 'we' (laws or rules of phonology, syntax, or semantics) are nested" (Zheng 2012). There are interactions among the dictionary user (I), compiler (you), sociocultural norm (we), dictionary (it) and other objects (they) in the real world or virtual space.

Based on the model (Figure 1), the relationship between the dictionary (it) and its user (I) should be rethought. The dictionary should be a friend that is always there, so faithful, helpful and thoughtful. This means that it should have such qualities as accuracy, functionality and adaptability. In addition, the interaction between the dictionary (it) and the other objects (they) in the physical environment is also meaningful. To improve its adaptability and customization, an e-dictionary is often embedded in or fused with the interfaces of learning activities like those of reading or writing software. Meaning-making and values-realizing are in the cycle of perception and action involving dictionary compilation and use.

Another illuminating insight that ecolexicography can gain from ecolinguistics contributes to an upgraded understanding of its overall framework. Steffensen and Fill (2014) point out four ways the language ecology has been conceptualized as a symbolic ecology, a cognitive ecology, a natural ecology, and a sociocultural ecology. Similarly, in terms of ecolexicography, a symbolic ecology can be understood as the semantic and semiotic ecology in a dictionary. A cognitive ecology of lexicography involves dictionary compilation/ design as dialogism and dictionary use as distributed cognition. The two constitute the microlevel of ecolexicography. At the macrolevel, ecolexicography should be committed to serving the linguistic, natural and sociocultural ecologies. The differentiation (and complementarity) between the microlevel and the macrolevel of ecolexicography mirrors the exoecological vs. endoecological division in ecolinguistics.

The endoecological position or the microlevel of ecolexicography, an obvious lacuna in literature, needs to be delineated to form a complete framework. This article aims to take a small step toward addressing the gap by revisiting ecolexicography as a new paradigm.

\section{Ecolexicography at the micro-level}

\subsection{The semantic and semiotic ecology in a dictionary}

Some scholars (e.g. Liu 2015) hold that the dictionary as a complex system can be symbolically compared to an ecology in two senses, semantic and semiotic.

First and foremost, the complicated semantic system of a dictionary is comparable to an ecology where meaning is like energy. Meaning flows and expands (Liu 2017), just as energy flows and circulates. As an ecological system, an e-dictionary is even more open and dynamic than a paper dictionary. There are interactions among the diverse members in this ecology, including 
cooperation and competition. Its components or communities are conceptually linked together as an integrated whole in a hierarchy. This organic whole is served by the dictionary macrostructure, mediostructure and microstructure as well as other information components that are themselves reciprocally conditioned. The macrostructure is the form and size of a dictionary, the mediostructure refers to its system of cross-referencing which can create textual cohesion, and the microstructure means its lexical entries or articles. Figure 2 roughly illustrates a pyramid of the dictionary semantic(-functional) ecology.

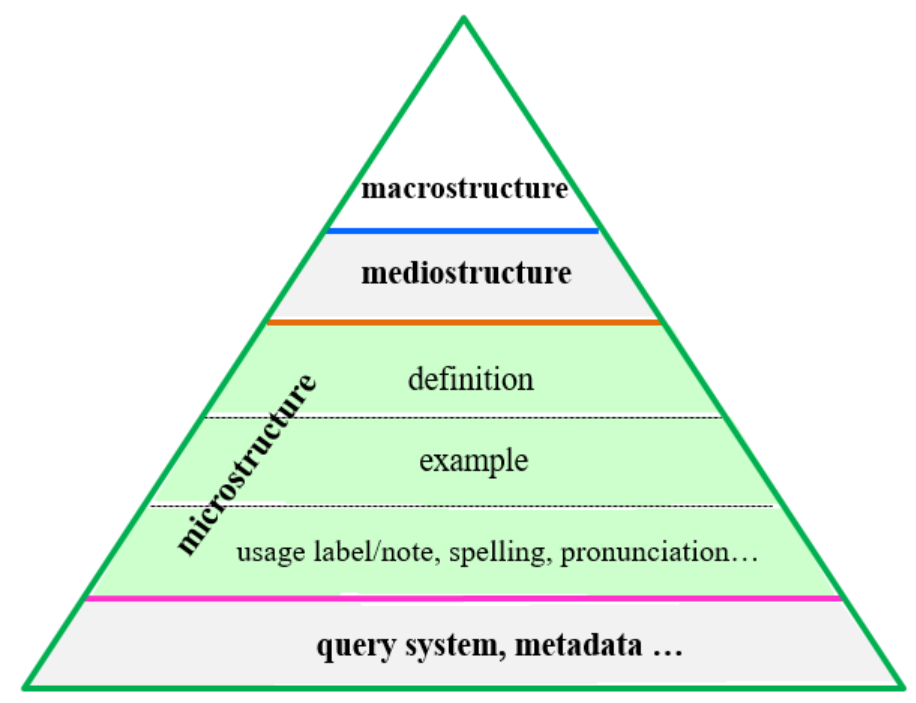

Figure 2: Pyramid of the semantic(-functional) ecology of a dictionary

The macrostructure of a dictionary is like an overall guide or a head that leads the whole semantic ecology on the top. The mediostructure is a network under the macrostructure. In the digital era, cross-references between words by hyperlinks easily connect entries and reinforce the mediostructure. The microstructure is the main body of a dictionary where definition acts as the core of meaning representation, playing a key role in stating or explaining the meaning of a word or phrase. A definition is often complemented by the illustrative examples ("examples" hereafter) under the same sense. Examples can reinforce meaning explanations, illustrate collocations and colligations, and contextualize for cultural, stylistic and pragmatic implications (Xu 2009: 12, 26-29). Many examples are transformed (i.e., simplified for children) from authentic sentences to meet the particular purposes of a dictionary, a lexicographical process like crop improvement in the biological ecology. Other microstructure components, such as spelling, pronunciation, usage notes and labels, also participate in the co- 
construction of meaning, serving behind as a guide to the microstructure. Other information components (query system, metadata etc.) are backgrounded on the bottom of the ecology. They act as the supporting system.

Furthermore, the semiotic system in a dictionary can be regarded as an ecology that is increasingly diversified in the digital era. In an e-dictionary, there are three major categories of multimodal meaning-making devices: written language, audio presentation of the verbal elements, including human voice recordings and synthesized speech, and other devices (Lew 2010), like pictures, silent animations, video clips, hyperlinks, floating tips and typography. Based on Multimodal Discourse Analysis (Kress and Van Leeuwen 2006) the choice of semiotic modes, and the cooperation and interaction among different modes are important for the dictionary ecology (Liu 2015).

If the semiotic ecology is examined hierarchically from a Systemic-Functional perspective, it can be stratified into three levels by following Rossi and Sindoni (2017): (1) semiotic systems (i.e. ideational, interpersonal and textual metafunctions or meaning potentials); (2) semiotic resources (i.e. instance or realization); (3) semiotic components (i.e. elements that can be unpacked from a resource and that concur to the instantiation of texts). They represent different levels of abstractions. Figure 3 illustrates the different strata proposed in our analysis.

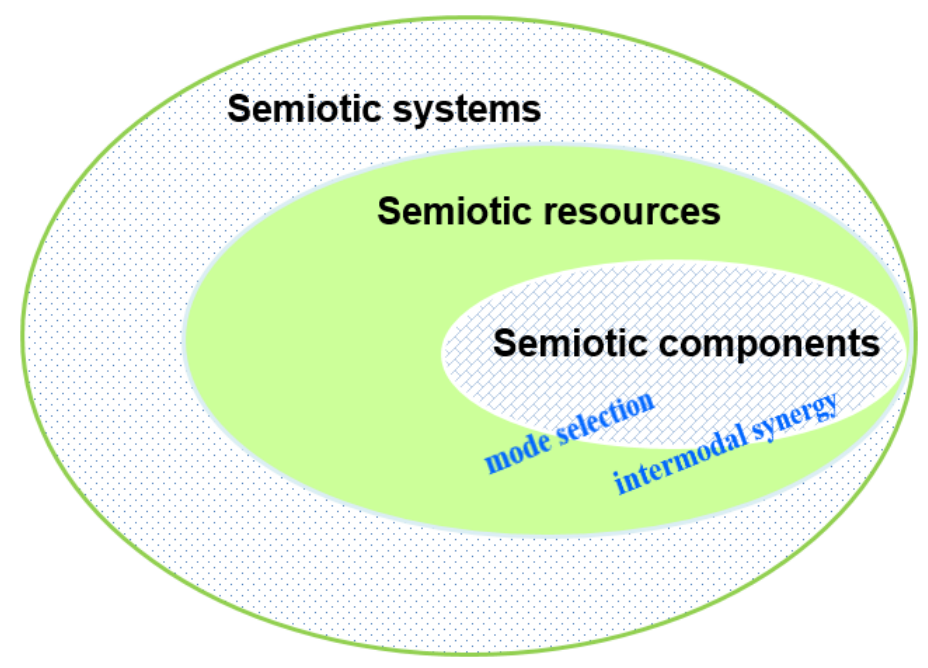

Figure 3: Stratification of the semiotic ecology of a dictionary

In brief, the semantic ecology is organized holistically by the synergy of multimodal devices, so that the whole is more than the sum of its parts. 


\subsection{The dialogicality in (e-)dictionary compilation/design}

Dialogicality means the dynamic abilities of human beings to take part in interactions with others and with sociocultural contexts as well as physical environments (Linell 2009: 368). Meaning or sense is co-constructed by dictionary compilers/designers and users, and it is not local. In the era of Web 2.0 and Web 3.0, there are more chances for them to have dialogues to make meaning/ sense. Problems such as lack of customization and information overload in dictionaries (Gouws and Tarp 2017) can be alleviated with a dialogical perspective.

Compared with paper dictionaries, e-dictionaries provide users with more chances of participation and interaction, facilitating compiler-user or even user-user dialogues and greater flexibility in use (cf. Liu 2017). Many e-dictionaries invite users to contribute entries or make comments on them (Granger 2012). They afford user customization. To take a previous version of Jinshan Ciba English Dictionaries (iCIBA) as an example, classified information was provided and its users could choose the type of examples they wanted. There were also buttons users could click to report a wrong example to the designer, praise a good one "in public" and save a useful one for his or her own use. Figure 4 is a screenshot of its entry of "ecological" (captured on Jan. 20, 2018) ${ }^{3}$. We have added English translations for its customization and interaction buttons.

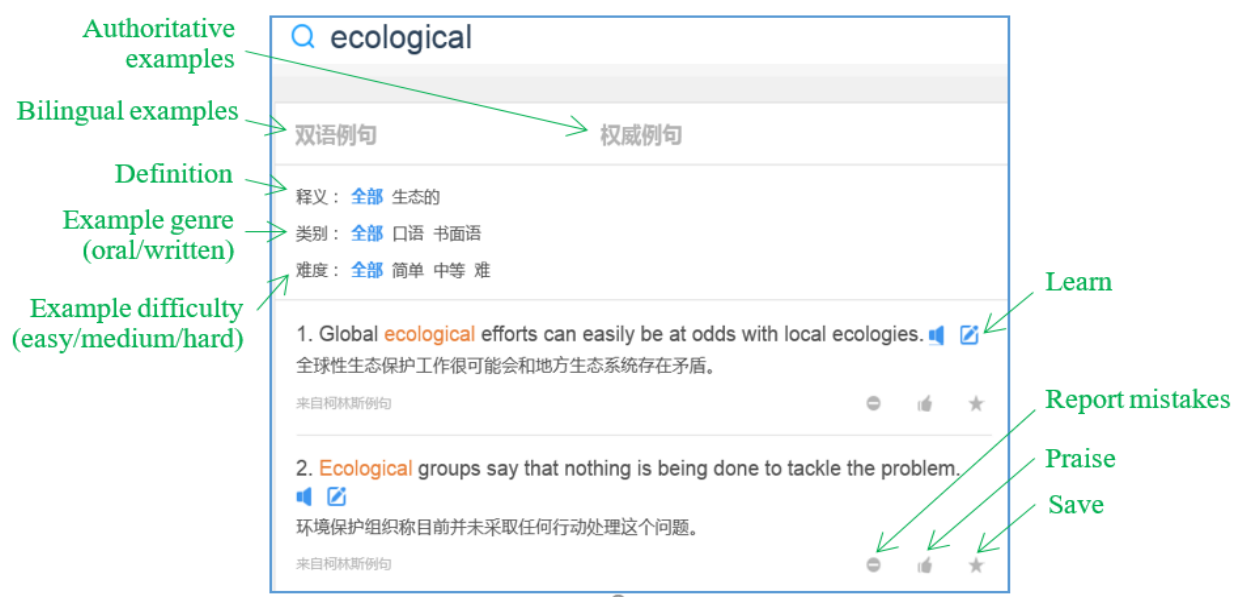

Figure 4: Customization and interaction buttons on the interface of $i C I B A$

It is advisable for e-dictionary designers to consider the user's ecological niche and allow co-selectivity and co-creation of meaning and value ${ }^{4}$. Learners' goals and needs could be scaffolded and transformed by design. This suggestion is broadly informed by distributed language, in that first-order dynamic action should be at the fore of second-order static prescription (Cowley 2011). The 
design based on the traditional concept that, on one hand, there is an objective, absolute authority of dictionary meaning, and on the other, there are users who use this absolute value-free tool, should be rethought (Liu, Zheng and Chen 2019). From the ecological psychological perspective (Gibson 1979), dictionaries can be considered having affordances for certain actions, such as for supporting enjoyment of reading, and for clarifying a statement. The ways in which actions connect dictionaries and users should result in changes in both artifacts and the agent (cf. Zheng 2012). Therefore, how dictionaries are designed can have a direct influence on learner behaviors.

Besides having more dialogues between dictionary compilers/designers and users, the ecology of an e-dictionary is filled with more different voices than that of a paper dictionary. Pop-up windows, for example, are used for projecting the voices of advertisers. With the social force of marketization, dictionary companies have to attract funding from advertisements to maintain the dictionary. Creating a more heteroglossic and noisy atmosphere, advertisements add to the complexity of the semantic ecology and may often distract users' attention in their cognitive processes. By heteroglossia, we mean a diversity or hybridity of voices and styles of discourse in the dictionary ecology as an extension from lexicographical dialogism ${ }^{5}$.

\subsection{The distributed cognition in (e-)dictionary use}

In ecolexicography, "distributed cognition" can be understood in both narrow and broad senses. In a narrow sense, the page layout of e-dictionaries usually looks less cluttered and the user's cognition involved in consultations is not restricted in a fixed manner. In a broad sense, cognition is distributed over different systems, such as brain, body, computers, instruments, aspects of the environment at large (Steffensen 2015).

The digital revolution of dictionaries "has removed constraints on size and format, paving the way for multi-faceted, flexible and rich representations of word meaning and use" (Fellbaum 2014). In densely printed pages of text, reading is often linear and strictly coded (Van Leeuwen 2005: 204). The onetime display in a fixed order might leave the users in a passive state of reception (Liu 2017). Large bands of space can be found in contemporary designs, suggesting the lightness of the reading experience. Spatial resource competition is less fierce.

In an e-dictionary, individual examples are often placed in separate paragraphs, and this makes them more readable than those densely printed in paper dictionaries. A distinctive type of vertical composition for examples in smartphone or tablet dictionary applications (apps) has been identified from Fayu Zhushou French Dictionaries (a most popular French dictionary app in China), where elements are mostly placed into equally sized tiles which could be swiped across to see more (Liu 2017). This way of organizing information allows contents to be textually linked as choices of the same order since tiles of the 
same size also achieve textual linking or rhyming, alongside that accomplished by color and fonts (Zhang et al. 2015). This creates visual harmony in the dictionary ecology, decreasing the difficulty of reading on a small screen. Also, there is added convenience of the ability to zoom in and out, not to mention the possibility to blend with other assistive technology to aid the visually impaired and those with poor eyesight. Users can make use of the convenient features of copying entries and exporting to other applications, or sending selected text through messenger applications.

E-dictionary information can be presented in an array of interlinked web pages and media networks, enabling e-dictionary users to navigate and choose their own pathways through this semantic ecology. Users can change dictionary settings (like interface style ${ }^{6}$ ), and make bookmarks, tailoring the use according to their own needs (ibid.). For instance, as shown by Figure 4 , the "Learn" button at the end of each example can be clicked to start a timed activity of memorizing an example, inviting the user to put the disordered words of an example sentence in good order. In the online Longman Dictionary of Contemporary English (LDCE), a collocation in its examples is highlighted with an underline and boldface font when the user's mouse cursor hovers over it (Liu 2017). During such human-computer interactions, a solid line emerges, giving readers a sense of the formation of the bundle/collocation (ibid.). This certainly involves distributed cognition.

In addition, because cognition is distributed across different places and contexts, effective lexicographic solutions should be suited to the needs of a particular user in a particular situation (Lew 2012), especially outside the classroom. For example, smartphone dictionary apps, due to the nature of portability, can work as flashcards for learners to carry with them. The smartphone can be used to scan an unfamiliar word for its meaning or translation and the user can add it to a wordlist for learning. Learning becomes more contextualized and meaningful when tied to learners' lives outside academia, and mobile devices help achieve that goal (Godwin-Jones 2011). Dictionary use, in turn, can transform language learning behavior as distributed cognition.

Furthermore, education in e-dictionary use can be provided from an ecological-dialogical perspective. This means that learning happens in an ecology with interactions between dictionary users and designers, between learners and teachers, and among learners (Liu, Zheng and Chen 2019). Dictionary use can be a result of a meaningful situated activity in which users need to consult a dictionary to understand meaning (Zheng 2012). Action-based activities can be better realized if instant support can be provided in a specific situation (Zheng et al. 2015) with a smartphone dictionary. Also, situated and actionbased activities can integrate with dictionary user training in a natural way.

In brief, with the proper use of semiotic resources, e-dictionaries can facilitate distributed cognition effectively. As a result, the role of the dictionary user changes from a passive receiver of meanings to an active explorer of senses. Users are unable to maximize a dictionary as a companion resource because 
dictionaries are conceptualized as an object that supplies predefined meanings. This article explores rethinking that a dictionary is a relational component of a distributed cognitive system along with users and compliers. Thus, the use of a dictionary in this new thinking helps make meaning with the distributed system.

\section{Ecolexicography at the macro-level}

\subsection{Lexicography and the ecology of language}

A dictionary is a good tool for outsiders (non-native speakers) to learn the language, and for insiders to document their language (Lee 2017: 5). The dictionary community is situated in its language habitat, and provides a prerequisite for the recording and development of natural language life. Etymology dictionaries play a most important role in documenting the minority languages which could be endangered because these languages contain and offer unique experiences of nature and knowledge, which have to be saved for future generations - especially in the sense of sustainability (cf. Bang and Trampe 2014). An average of 6 languages are disappearing from this world every year, and 1,531 languages among 7,102 are classified as threatened or shifting (Lee 2017: iii), so there is much work to do to revitalize endangered languages. If possible, a holistic approach (Tsunoda 2005: 231-233) may be the best way to document one language, covering various aspects of a language, including phonology, morphology, syntax, discourse, semantics, and vocabulary.

Methodologically, compiling dictionaries for endangered languages is different from that for languages that are not under the threat of extinction (ibid.). For the former, lexicographers should highlight the changes in the manner in which it is used, the reduction of the number of its different registers, as well as changes and simplifications in its structure, and lexical composition, and semantic changes in its lexicon, with all this resulting from a linguistically-oriented endangerment of its traditional form (Wurm 2007). At the same time, they should be aware of the sociolinguistic aspects, like the declining use of the language by shrinking numbers of its speakers, and the reasons, and circumstances of such events (ibid.).

Although some dictionaries documenting endangered languages are products of individual or community efforts, like Buk Bang Sinda (BidayuhMalay-English Dictionary), most of them result from a "top-down" process. Lexicography can be regarded as a part of the language planning of state agencies. Language planning was first introduced in 1959 by the ecolinguistic forerunner, Einar Haugen, and the subject has become increasingly important as awareness of the socio-political nature of language choices in multilingual/ multi-dialectal communities has grown (Jones 2015: xiii). The ideologies underlying language planning strategies are often, at least partly, attributable to what has been described as language policy (ibid.). The first step in saving dying 
languages is to persuade the world's majorities to provide opportunities for the minorities among them to speak with their own voices. Compiling dictionaries of minority languages may need teamwork among lexicographers, sociolinguists, ethnographers and anthropologists. An ecological perspective would be preserving not only languages but also the social group. Without people and community, what would language be for?

Bosch and Griesel (2020) proposed an innovative way of documenting and preserving nine African languages in a digital lexical database, the African Wordnet. They claim that such a database becomes a useful resource for natural language processing, consolidating dispersed indigenous knowledge collected from a variety of sources in a digitized hierarchical wordnet structure.

\subsection{Lexicography and the ecology of socio-culture}

It is generally acknowledged that dictionaries are not value-free representations of languages and the world. Illustrative examples, for instance, are imbued with lexicographic intentions and "constitute a repository of the common values and interests of the society whose language is described" (Béjoint 2010: 202). Dictionaries should convey ideologies in such a way as to promote the positive development of human society, including peace, justice, equality and sustainability. Unavoidably, social learning must be moral learning (Hodges and Baron 2007), and values are not properties of persons or objects, but relationships and the demands that the ecosystem places on those relationships (Zheng 2012). As frames are mental structures that shape the way we see the world and we know frames through language, morally based framing7 is everybody's job (Lakoff 2014: 116), including lexicographers.

In the field of critical lexicography, scholars have examined such issues as gender (e.g. Hoey 2001; Moon 2014), racism and religion (e.g. Willinsky 1994; Ogilvie 2013), and politics and class (e.g. Ezquerra 1995). Previous studies (e.g. Benson 2002; Hornscheidt 2008) reveal how imperialism, racism and colonialism are naturalized in dominant monolingual dictionaries, such as the Oxford English Dictionary. Chen $(2015,2017)$ argues that bilingual lexicography is a complex site of ideological struggle and recontextualization of lexicographical discourse across cultures and contexts, resulting in the transformation and transfer of meaning. Recontextualizers of A New English-Chinese Dictionary (NECD), for instance, attempt to de-politicize the words and examples in the source dictionary by using such discursive strategies as deleting, replacing, and re-signifying (ibid.). When we successfully reframe dictionary discourse, we change the way the user sees the world. Because language activates frames, new language is required for new frames (Lakoff 2014: 15).

Many examples in Big Five dictionaries are found to embody ideas and values which are biased or politically wrong. For instance, COBUILD8 presents "Possession of cannabis will no longer be an arrestable offence" for the entry of "arrestable", "I started smoking grass when I was about sixteen" for "grass" (= mari- 
juana), and "Up to two thirds of 14 to 16 year olds admit to buying drink illegally ..." for "admit" (see Part A in Appendix II). These examples, scattered in different entries, could co-build a harmful frame of drugs in the user's mind: Using drugs is a good experience; People can legally be drug abusers. Furthermore, a 2020 slang phrase, "Funny mud pee" (Go fuck yourself), included in the crowdsourced Urban Dictionary (https://www.urbandictionary.com/define. php?term=Funny $\% 20 \mathrm{mud} \% 20$ pee), is an example of racism recontextualized from the Chinese-speaking to English-speaking world. It is a Chinglish curse created by Chinese social media users posting on Twitter extensively amid the global outbreak of COVID-19 in response to those tweets labeling COVID-19 as "Chinese virus" or "Wuhan virus". The lexeme is used in the media as something bad and must be eliminated or annotated properly to avoid harm or destruction of the global community.

Information in dictionaries should be selected and presented in such a way as to respect various cultures. In $L D C E$, the word "pig" is defined as "a farm animal with short legs, a fat body, and a curved tail. Pigs are kept for their meat, which includes pork, bacon, and ham" (https://www.ldoceonline.com/ dictionary/pig). From a socio-cultural perspective, this definition is incomplete since it is not true that pigs are kept for their meat by all communities. In some cultures, pigs are kept as pets. Muslims don't eat pork and they would feel uncomfortable when reading such a definition.

In sum, the relationship between ideology and dictionary compilation is not a new topic in lexicographical studies, but most previous research has explored the topic from the perspective of dictionary compilers or designers. Attempts should be made to study the relationship from the perspective of the response of users regarding monolingual and bilingual/multilingual dictionaries. Users have the power to accept or reject a dictionary or a definition or example in an entry that is ideologically similar to or different from their own thinking, and ideology-oriented dictionaries can only realize their purpose in the right place at the right time (cf. Li 2012). After all, dictionary use - as a part of languaging - can promote "individualized values-realization" (Zheng 2012). That is a new research orientation that macro-ecolexicography can explore.

\subsection{Lexicography and the ecology of nature}

Language can inspire us to destroy or protect the ecosystems that life depends on. For example, the language of advertising can encourage us to desire unnecessary and environmentally damaging products, while nature writing can inspire respect for the natural world (Stibbe 2015: 174). Dictionaries are committed to the task of ecosystem protection, and help address such overarching ecological challenges as biodiversity loss, food security, climate change, water depletion, energy security, and chemical contamination. At the very beginning of dictionary design, the headwords which are closely related to the ecosystem can be selected in a separate list and given special attention. Wordsmyth Kids Dictionary 
(WILD, a popular children's dictionary) offered to guide children to explore words about the world, putting them in two modules: those about the city and those about nature. It seems that WILD embodies such a destructive frame: It is normal that urban residents stay away from nature since they don't belong to it. In other words, an implied contrast between city and nature may convey ideological ideas against human-nature oneness.

In writing definitions, lexicographers can implicitly or explicitly reinforce the users' awareness of environmental protection. This educational function of dictionaries can never be underscored enough. Take the word "ermine" as an example, in Cambridge English Dictionary (CED), it is defined as "expensive white fur with black spots that is the winter fur of the stoat (= a small mammal) and is used to decorate formal clothes worn by kings, queens, judges, etc." (https://dictionary.cambridge.org/dictionary/english/ermine). This definition has connotations of the merciless killing of the animal, and it implies the glory of wearing ermine clothes with a focus on the economic benefits from ermine trade. There are similar definitions in LDOCE5, e.g. "the skin or fur of some types of seal, used for making leather or clothes" for the entry of "sealskin", and "strong soft leather made from the skin of a deer or goat" for "buckskin" (see Part B in Appendix II). This "reification" (Trampe 2001: 1) of animals may constitute biased representation. The embedding of humans in the larger systems that support life is forgotten or overlooked (Stibbe 2014: 585), making it possible to treat animals as commodities at the service of human needs (Fusari 2018). This makes the dictionary evade its function of environmental protection, similar to or perhaps even worse than "animal erasure" (Stibbe 2015: 155). Lexicographers should be aware that dichotomic representations opposing animals to humans are deeply rooted in language, and make use of lexical or grammatical devices to create public consensus in favor of effective conservation of biodiversity (cf. Fusari 2018).

While choosing examples for an entry from the corpus, lexicographers could zoom in on the texts and discourse of ecological importance, and then choose and adapt examples carefully. In Merriam-Webster's Learner's Dictionary (MLD), examples are creatively designed for the first sense of the headword "nature" (http://www.learnersdictionary.com/definition/nature). As Figure 5 shows, the six examples are coherently organized and the second ("She is a real nature lover.") aims to cultivate love of nature in particular. The way the examples are ordered is carefully chosen. As their linguistic difficulty increases, they loom progressively into an integrated discourse that communicates important educational messages: nature is beautiful, it deserves our love and study, we can explore it (including its color) by taking photos, and we should conserve nature. The examples construct a harmonious semantic ecology, embodying human-nature oneness with schematic experience and knowledge ${ }^{8}$. 
http://lexikos.journals.ac.za; https://doi.org/10.5788/31-1-1648 (Article)

For a Better Dictionary: Revisiting Ecolexicography as a New Paradigm

1 [noncount] also Nature

a : the physical world and everything in it (such as plants, animals, mountains, oceans, stars, etc.) that is not made by people

" the beauty of nature

" She is a real nature lover. = She really loves nature. [=she loves to spend time outdoors]

- He devoted himself to the study of nature.

- That is a color not found in nature.

- nature photography

- nature conservation

[-] hide examples

Figure 5: Screenshot of an entry in $M L D$

Compilers of ecologically-minded dictionaries can construct subcorpora of texts about the ecosystem and environmental protection, like personal virtual corpora based on the Wikipedia Corpus on the platform of Brigham Young University (https://corpus.byu.edu/wiki/). Based on such ecologically-oriented corpora, lexical databases can be constructed and shared by world lexicographers. EcoLexicon is such a terminological knowledge base on the environment (http://ecolexicon.ugr.es) with terms in six languages: English, French, German, Modern Greek, Russian, and Spanish. It is the practical application of Frame-based Terminology to configure specialized domains on the basis of definitional templates and create situated representations for specialized knowledge concepts. We should develop an awareness of green lexicographical technology and improve ecological efficiency in the ecosystem of lexicography. Then the dictionary discourse can be reframed effectively, eliminating destructive frames systematically. For instance, the frame of "Animals are resources for human abuse" (see Part B in Appendix II) seems prevalent and deeply entrenched in "Big Five" dictionaries, and this systematic problem could be solved with the help of ecologically-oriented databases.

Definitions and examples should try to reflect the reality and dynamism of bio-ecology. Take the headword "romaine" as an example, it is defined as "a type of bitter-tasting lettuce with long leaves" in LDCE (https://www. ldoceonline.com/dictionary/romaine). But in actual fact, this vegetable sold in the supermarket now is not bitter at all, perhaps as a result of long-time crop improvement. So, this definition may either be against the reality of bio-ecology or fail to reflect its changes.

Proper notes or labels concerning ecosystem protection could be added to an entry of ecological importance. In general-purpose dictionaries, encyclopedic information could be added by referring to specialized dictionaries on 
ecology, such as Dictionary of Environment and Ecology. This integration of linguistic and non-linguistic information corresponds with the holistic view of meaning and the functional theory of lexicography (Tarp 2007).

Serious ecological destruction has already occurred and more would be inevitable, so resilience to further environmental changes is necessary for finding new forms of society (Stibbe 2015: 15). This resilience can be properly embodied in lexicography, which connects the natural and social layers around dictionaries.

\section{Discussion}

\subsection{A unified framework of ecolexicography}

Based on Steffensen and Fill's (2014) conceptualization of the language ecology as a symbolic, cognitive, sociocultural and natural ecology, we have identified five new dimensions that an ecological perspective can add to lexicography: symbolism, cognition, language, socio-culture and nature. These dimensions fall into two levels of ecolexicography: microlevel and macrolevel. The first two dimensions (symbolism and cognition) constitute the microlevel of ecolexicography. The other three dimensions (language, socio-culture and nature) form the macrolevel. The two levels can be regarded as two domains of the area, micro-ecolexicography and macro-ecolexicography. We tentatively propose a framework of ecolexicography unifying the two levels or domains (see Figure 6).

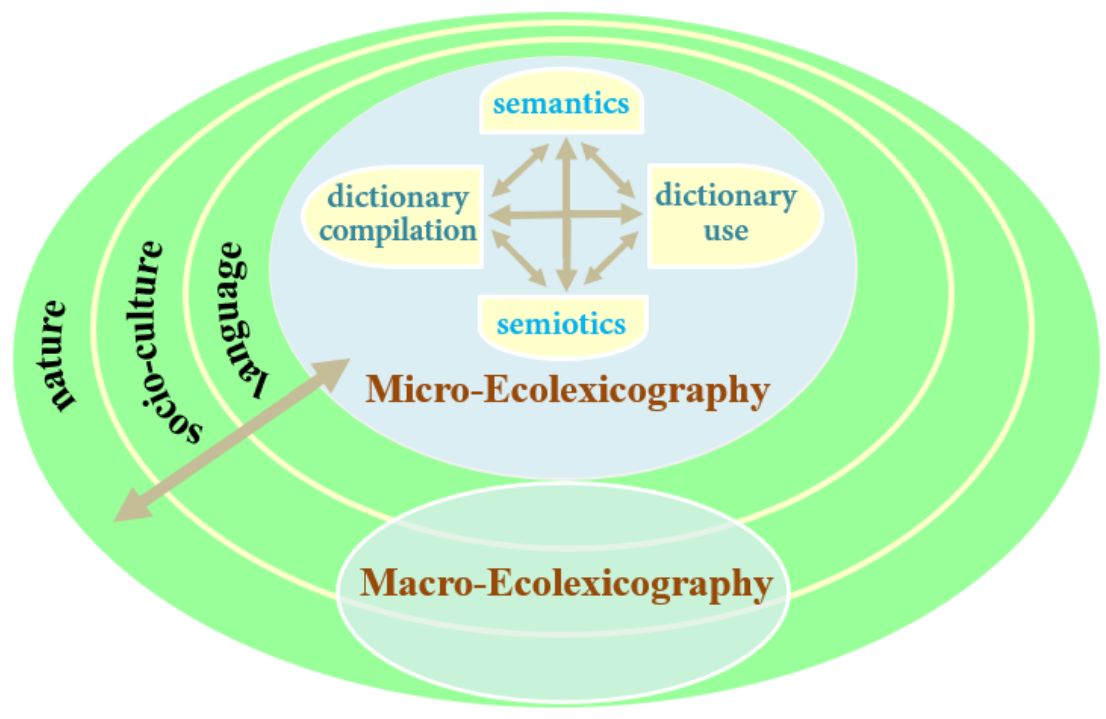

Figure 6: A multidimensional framework of ecolexicography 
We may draw insights from multimodal discourse analysis to interpret the layout of Figure 6. According to the information value principles for visual composition proposed by Kress and Van Leeuwen (2006: 197), it is fundamentally a structure of "Center and Margin". In this model, micro-ecolexicography is the Center and it forms the nucleus of the space. Three outer layers (the Margins), language, socio-culture and nature, "wrap" or contextualize the cognitive processes of dictionary compilation/design and use as well as the dictionary itself. These layers create a gradual and graded distinction between Center and Margin. In micro-ecolexicography, dictionary compilation is on the left denoting the Given (i.e. old information) while dictionary use is on the right denoting the New (i.e. new information). Semantics is on the top representing the Ideal while semiotics is on the bottom representing the Real. For something ideal means that it is presented as the idealized or generalized essence of the information while the Real presents more specific information (e.g. details), more down-to-earth or practical information (ibid.: 186-187).

The framework represents an interactive ecology, and it refreshes our understanding of the major tenets of ecolinguistics through a lexicographical lens. Micro-ecolexicography is the origin and prime mover of communication. The double-headed arrows in Figure 6 indicate dialogues and interactions among communicative participants or affordances as well as ecologies, symbolizing dynamism or circulation of the ecosystem. There are underlying linkages and interactions between every two of the four "layers" (dictionary, language, socio-culture and nature).

Micro-ecolexicography may focus on e-dictionary design and use in the digital era while macro-ecolexicography highlights dictionaries' educational function and lexicographers' commitment to three interrelated ecologies (nature, socio-cultural and language) and can be attentive to various types of dictionaries.

\subsection{Rethinking the methodology of ecolexicography}

The methodology of ecolexicography should be reconsidered as a new paradigm. Ecolexicographic thinking is concerned with complex systems and diverse situations. It is arguable to place dictionaries within a distributed cognitive system and view them as such a system. Holistic, systematic and integrative methodology is essential to ecolexicographical practice and research.

Micro-ecolexicography could benefit a lot from the following methodologies: (1) multimodal discourse analysis for building a semiotic and semantic ecology of the dictionary; (2) information technology (e.g. data mining for tracking user feedback) and transdisciplinary approaches to user research for enhancing dialogicality and distributed cognition.

User research should be a key theme of micro-ecolexicography. It can be done before a dictionary is compiled so that preventive measures could be taken by its designer. A statistical method widely used in psychometrics, latent 
class modeling, should be a useful tool for investigating user intentions and attitudes. It identifies the underlying or invisible subgroups/categories (e.g. motivation) in the population, and can be introduced to large-scale surveys (see Liu, Zheng and Chen 2019 for an example). Surveys with latent class modeling could offer more important pointers for dictionary customization than traditional surveys that are generally based on visible subgroups (e.g. gender) of dictionary users.

However, when investigating socially sensitive attitudes like racial prejudice through a survey or interview, one should be aware that people are often motivated to self-report unprejudiced and egalitarian beliefs. To bypass socialdesirability bias, an experimental paradigm of cognitive psychology, the Implicit Association Test (IAT), is recommended. As an influential measure of people's unconscious attitudes, IAT is less subject to deliberate control and potential distortion than interviews or focus groups. Such interdisciplinary methods have advantages over traditional approaches in exploring underlying values and frames in the minds of dictionary users and even dictionary designers.

Macro-ecolexicography could be nourished by: (1) Critical Lexicographical Discourse Studies for globally critiquing the dictionary discourse; (2) Corpusbased Frame Analysis (CFA) is recommended for revealing ecologically (non)destructive ideologies and frames in dictionaries specifically (cf. Lyu and Liu, in preparation); (3) ways of reframing the dictionary discourse.

Chen's (2019) Critical Lexicographical Discourse Studies (CLDS) not only offers a theoretical rationale for revisiting ecolexicography (see Section 2.2.1), but also specifies how to critique the dictionary discourse. With a focus on interdiscursivity, it compares the dictionary discourse with other types of texts. According to Chen (2019), analysis of the order of discourse is first done to disclose the latent social rules that govern the production of discourse. Then an interactional analysis is made, which consists of interdiscursive analysis, and linguistic/semiotic analysis (e.g. identifying how the lexicographic discourse is interdiscursively related to other discourses and genres, and analyzing lexis and clauses). Such an integrated analysis of textual and social structures helps uncover the internal relationship between them, with the situated contexts of dictionaries taken into consideration (ibid.).

If CLDS provides a macroscopic view for reframing the dictionary discourse, frame analysis, a common tool for critiquing or promoting ecological discourse, is perhaps more microscopically oriented. Corpus-based Frame Analysis could be more reliable than traditional frame analysis since it exploits objective evidence of corpus data for comparative analysis of ideologies and frames. Examining the semantic roles and their interrelations within a text or across texts via corpus analysis can reveal the ideologies and cognitive frames behind them. We also draw insights from previous scholars (Blackmore and Holmes 2013: 42; Stibbe 2015: 46-61) who have introduced the social-valuesoriented frames to ecolinguistic research from the perspectives of cognitive semantics and discourse studies. 
Corpus-based Frame Analysis consists of four main steps (see a more detailed illustration in Lyu and Liu, in preparation):

(1) randomly sampling definitions and/or examples from a dictionary and building them into a mini-corpus of dictionary discourse (D-corpus in short);

(2) identifying destructive discourse and analyzing frames behind the sample data (see Endnote 2 for the procedure of frame analysis), examining their relations and classifying them into a hierarchical network when necessary;

(3) using keywords to extract relevant discourse and analyze frames from an authoritative (and presumably balanced) corpus (namely B-corpus) or the corpus the dictionary claims to be based on (if available), and comparing the B-corpus frames with the D-corpus frames;

(4) based on the features and distribution of destructive frames, exploring the possible reasons for their existence with contextual factors considered, and rethinking its social accountabilities and possible solutions.

A keyword may have numerous frames in the B-corpus, and only those reflected by the most frequent collocations are considered. For example, for the patterns "A motivate B to do" and "A lead B to do" in the dictionary, the most frequent collocations in COCA turn out to be: factors motivate/lead somebody ( $\mathrm{sb}$ ) to do something (sth); sth motivate students to do sth; sth lead people to do sth; sth motivate sb to develop sth; sth lead sb to believe sth else. As Part A of Appendix II shows, LDOCE5, backdropped against COCA, creates a spouse killing frame through these examples: "We may never know what motivated him to kill his wife" and "What led him to kill his wife?". This is a biased representation of both real life and language use.

Destructive frames have their own linguistic and distributional features as they may be reflected by different (numbers of) definitions and examples in the dictionary discourse. The reasons for their existence can be traced to these features. Some frames are widely distributed and may form a complicated network. According to Appendix II, the frame of animal abuse seems far more complex (divisible into four subtypes in this case) and perhaps more severe than the frame of plant abuse, so the former may deserve more attention and a systematic solution is necessary.

The ultimate purpose of CFA is to reframe the dictionary discourse to avoid biased representations of reality. Dictionaries are supposed to capture the most typically shared values and ethics of a community to represent them in the definitions and illustrative examples (see Figure 5 for an example). At least, such problems as Trampe (2001) identified (e.g. reification, defamation, disguise) should be rectified. We'd like to recommend five ways of reframing the dictionary discourse: warning, commenting, refining, questioning and neutralizing.

The most straightforward way of reframing is to give a warning against 
immoral and illegal practices. For instance, a definition of "crocodile" in LDOCE5 ("the skin of this animal, used for making things such as shoes", see Part B in Appendix I) may be inadequate because it seems to ignore that crocodile is a species at risk of extinction. This definition could be refined to reveal the fact, or a note/warning could be added (e.g. "The crocodile is an endangered animal and should not be killed at will for profits). Another direct way is to enhance existing linguistic data by commenting on immoral values and improper behaviors. For instance, one could present "Experimentation with cannabis is illegal", rather than "experimentation with cannabis" as found in LDOCE5 (see Part B of Appendix I).

The third way of reframing, refining, means changing the current definitions or examples moderately, often by adding modifiers or other descriptions of details. Take the OALD9's entry "hashish" as an example, it is good to end with a warning ("Use of the drug is illegal in many countries", see Part A in Appendix I). However, its definition ("a drug made from the resin of the hemp plant, which gives a feeling of being relaxed when it is smoked or chewed") may embody a problematic positive attitude to drug use, and one could refine it by adding words like "misleading" or "dangerous" before "feeling". This is an implicit and subtle way of reframing.

The last two ways of reframing, questioning and neutralizing, concern controversial or sensitive issues. Questioning means asking a yes-no or rhetorical question. For instance, for the entry of "nature", one could use the question "Do you think man is good or evil by nature?" rather than a statement "She is evil by nature". Neutralizing refers to adopting a neutral stance when dealing with conflicting definitions by different communities and cultures. When dominant voices in society have dictated meanings of concepts/words at the expense of other social beliefs, it is advisable to listen to different voices with an ecological view. For instance, hunting is considered differently between wildlife conservatories (and governments) and local communities in Africa. The former only restrict it to the tracking and subsequent killing of game by "licensed" parties (usually foreigners), typically with rifles, all-terrain vehicles and professional trackers/rangers, and regard the same activity by members of local communities (usually with dogs, snares, spears and bows and arrows) as "poaching" (notwithstanding that the locals consider their own activities as hunting too). Besides giving a neutral definition (e.g. "go after wild animals to kill or catch them"), an African-oriented dictionary could point out the different understandings of the government and local communities to avoid biased representations of socio-cultural reality. The inclusion of conflicting definitions, as a way of dictionary customization in this case, may lead the government to rethink their policies, and at the same time enhance local communities' awareness of the divergence. Most importantly, the entry should give a warning against the brutal killing of animals at will, and clarify the differences in semantic prosody among hunting (neutral), poach (negative) and cull (positive). We do not mean that lexicographers should be preoccupied with pro- 
viding only entries that are ecologically friendly. Sometimes, an eclectic and holistic approach is necessary for rebalancing cultural values for a sustainable society. ${ }^{9}$

\subsection{Limitations and future research}

Although the article offers refreshing insights into lexicographical research and practice, it is not free from limitations. The proposed approaches and models are still not substantiated with adequate empirical data from different types of dictionaries. The survey into "Big Five" dictionaries only covered 30 random pages from each of them. It was not an exhaustive retrieval of information for identifying all the destructive ideologies and frames. No investigation has been conducted into the intentions, attitudes and values of both dictionary users and designers. Furthermore, the five ways of reframing the dictionary discourse are far from enough to cover all the anti-ecological and anti-sociocultural problems.

There are theoretical and practical orientations for future research. Theoretically, eco-lexicographers still have to identify the principles similar to the succession and evolution of ecosystems, perhaps fruitful for illustrating the dynamism of different types of dictionaries. We need to reconsider, first, the values and concerns of traditional lexicography and, second, a context where ecologically oriented dictionaries compete with resources sustaining ideologies of consumption. Practically, more evidence should be collected to support the new paradigm of ecolexicography. Systematic investigations into dictionary discourse and dictionary use are needed by using techniques of data mining, machine learning and natural language processing. Different types or genres of dictionaries should be examined from an ecological perspective, and respective solutions can be found to improve them. A set of practical guidelines and methods for reframing the dictionary discourse should be developed.

Philosophically, we think that ecolexicography can gain inspiration from ancient Chinese worldviews of holism (focusing on the larger world than the body - the universe), interconnectedness, eclecticism and harmony (between the human and the cosmic, within society, and within the self). Although they might include "anthropocentric" interventions that entail ecologically constructive ideologies and practices, on the whole, they can help us engage in ecological awareness and deal with ecological crises. Different from the scientific tradition of viewing the world as separated physical parts and encouraging competitions (e.g. Darwinism), the Chinese cultural concept of "human-nature oneness" advocates altruism and tolerance (Lyu and Liu, in preparation). A harmonious view of language, mind and the world, and a new harmony of science, axiology and aesthetics are crucial (Huang and Zhao 2017; Zhou 2017) for a rebirth of lexicography in the digital era, an epoch of Anthropocene. 


\section{Conclusion}

To conclude, ecolexicography can be redefined as a new paradigm by adding symbolic and cognitive dimensions to the microlevel of a unified framework, and by upgrading the ontological, epistemological and methodological aspects related to this field. A redefined ecolexicography raises interesting questions. Besides proposing new terms including macro-ecolexicography and micro-ecolexicography, we have enriched the meaning of at least three groups of old theoretical terms or practices: (1) dictionary in/as a distributed cognitive system, distributed cognition, dictionary user identity, lexicographical interaction, dialogism and heteroglossia; (2) exoecological/endoecological position, values realizing, recontextualization; (3) frame analysis, user research, and lexical database construction. Ecolexicography as a novel paradigm is emancipatory, and could be a fruitful alternative to traditional practice and research, opening fresh paths and insights in an era of big data. It may help lexicographers solve the current problems with e-dictionaries in a new light, contributing to their role of serving the ecologies of language, socio-culture and nature. Additionally, it would be conducive to philosophical reflections on metalexicography.

Nevertheless, there is still a long way to go because there are many challenging issues. E-dictionary customization, for instance, is dependent on not only users' computer skills but also financial support for lexicographical projects. Dictionary compilation is limited primarily by the time and money available to do it.

\section{Endnotes}

1. "Big Five" refers to the five best-known English learners' dictionaries: OALD, LDOCE, COBUILD, CALD (Cambridge Advanced Learners' Dictionary) and MED (Macmillan English Dictionary).

2. As words are defined relative to frames, hearing/reading a word can activate its frame and the frames in its system in the brain (Lakoff 2010). Represented in syntactic patterns, frames involve semantic roles and their relations which are ultimately connected with people's cognitive frames (ibid.).

3. With over 20 million users, $i C I B A$ is said to be the second most popular dictionary app in China. Unfortunately, its latest version has no customization and interaction buttons as shown in Figure 4. Due to lack of data, we cannot find out if its designers would alter the entry in light of user feedback. We agree with one of the reviewers that designers' response to user feedback needs investigation because it enriches the meaning of dictionary editing/ revision as another potential basis for in-depth discussion under ecolexicography.

4. One of the reviewers suggested considering "the possibility of enhanced methodologies incorporating advanced online reach at the data-gathering stage of compiling the dictionary" to make potential users participate in the creation (rather than revision) of the dictionary. We think that it is a promising area of research. Additionally, we agree with the reviewer that "not all users will have the magnanimity to participate constructively" — some would condemn the whole dictionary just because of one entry they dislike, and "instead of co-creating 
meaning and value, they set out to defame the entire product and, thus, engage in 'destructive' tendencies against the dictionary". This proves the importance of ecolexicography in inculcating a sense of responsibility and correct values in dictionary users.

5. One reviewer holds that there may be ironic cases where an anti-ecological advertisement pops up ahead of ecologically sensitive entries, like dirty money sponsoring charity programs. This is one of the challenges eco-lexicography faces. Considering the varied nature and themes of advertisements, we suggest that dictionary developers be selective and refuse anti-ecological advertisements (see Dziemianko 2020 for the effect of advertising on online dictionary usefulness).

6. Customization of the interface style is important especially for the visually impaired or people with low vision who may wish to change the background color and light contrast (e.g. night theme) to adjust glare to read comfortably. We owe this idea to one of the reviewers.

7. Framing is the use of a story from one area of life (a frame) to structure how another area of life is conceptualized. Reframing is the act of framing a concept in a way that is different from its typical framing in a culture (Stibbe 2015: 47). A discourse can be reframed with concepts redefined for communicating new values.

8. One of the reviewers asked us to think of "he is evil by nature" as an illustrative example which may create a negative frame in the user's mind. One solution is to change the statement into a question (see Section 5.2).

9. We are thankful to one of the reviewers for the examples in this paragraph. S/he also mentioned the case of sanctioned culling of wildlife to reduce ballooning population sizes of specific species that threaten the environment. This kind of anthropocentricity, if unavoidable, may be justified. After all, humans form part of the ecosystem with other members of nature. Sanctioned culling of wildlife is different from animal abuse and killing at will. An ecological dictionary may allow for some flexibility and inclusiveness in treating entries that border on "ecologically (non)destructive ideologies". Eclecticism is a wise policy.

\section{Acknowledgments}

This work was supported by: the Philosophy and Social Science Fund of the 13th Five-year Plan of Guangdong Province of China [GD18XWW14]; the Philosophy and Social Science Fund of the 13th Five-year Plan of Guangzhou City of China [2019GZGJ24]; the Fundamental Research Fund for the Central Universities of China [XYZD201919, ZDPY202036] and the Double First-Class Construction Project [K5200690] of South China University of Technology; the MOE Project of Center for Linguistics and Applied Linguistics, Guangdong University of Foreign Studies. We'd like to express our deep gratitude to the editors and the reviewers for their constructive comments and suggestions.

\section{References}

\section{A. Dictionaries}

A New English-Chinese Dictionary (Century edition). 2003. NECD Compilation Group. Shanghai: Shanghai Translation Publishing House. 
Buk Bang Sinda (Bidayuh-Malay-English Dictionary). 2013. Kuching, Malaysia: Dayak Bidayuh National Association.

Cambridge English Dictionary. Cambridge: Cambridge University Press. https://dictionary.cambridge. org/dictionary/english/. Accessed on 28 Jan. 2020.

Collins COBUILD Advanced Learner's Dictionary (8th edition, COBUILD8). 2014. Glasgow: HarperCollins.

Dictionary of Environment and Ecology (5th edition). 2004. Collin, Peter H. (Ed.). London: Bloomsbury.

Fayu Zhushou French Dictionaries. Shanghai Qianyan Network Technology Corporation. An app downloaded from https://www.francochinois.com/v4/fr/app/download\#mobile. Accessed on 20 Jan. 2020.

Jinshan Ciba English Dictionaries (iCIBA). Jinshan Software Corporation. http://cp.iciba.com. Downloaded and consulted on 20 Jan. 2018.

Lexico.com (Oxford Dictionaries English). Dictionary.com and OUP. https://www.lexico.com/. Accessed on 12 Apr. 2020.

Longman Dictionary of Contemporary English. Pearson Education. http://www.ldoceonline.com/. Accessed on 25 Jan. 2020.

Longman Dictionary of Contemporary English (5th edition, LDOCE5). 2009. Mayor, Michael and Chris Fox (Eds.). London: Pearson Education.

Merriam-Webster's Learner's Dictionary. http://www.learnersdictionary.com. Merriam-Webster, Incorporated. Accessed on 12 Apr. 2020.

Oxford Advanced Learner's Dictionary (9th edition, OALD9). 2015. Deuter, Margaret, Jennifer Bradbery and Joanna Turnbull (Eds.). Oxford: OUP.

Urban Dictionary. https://www.urbandictionary.com. Accessed on 12 Apr. 2020.

Wordsmyth Kids Dictionary (WILD). https://kids.wordsmyth.net/wild/. Accessed on 13 Feb. 2018.

\section{B. Other literature}

Albuquerque, Davi B. 2018. As relações entre Ecolexicografia e Lexicografia Pedagógica (The Relations between Ecolexicography and Pedagogical Lexicography). Dominios de Lingu@gem 12(4): 20662101.

Baker, Paul. 2006. Using Corpora in Discourse Analysis. London: Continuum.

Bang, Jørgen Chr. and Wilhelm Trampe. 2014. Aspects of an Ecological Theory of Language. Language Sciences 41(A): 83-92.

Béjoint, Henri. 2010. The Lexicography of English: From Origins to Present. Oxford: Oxford University Press.

Benson, Phil. 2002. Ethnocentrism and the English Dictionary. London: Routledge.

Bergenholtz, Henning and Sandro Nielsen. 2006. Subject-Field Components as Integrated Parts of LSP Dictionaries. Terminology 12(2): 281-303.

Blackmore, Elena and Tim Holmes (Eds.). 2013. Common Cause for Nature: Values and Frames in Conservation. Machynlleth, Wales: Public Interest Research Centre.

Bosch, Sonja E. and Marissa Griesel. 2020. Exploring the Documentation and Preservation of African Indigenous Knowledge in a Digital Lexical Database. Lexikos 30: 1-28.

Chen, Wenge. 2015. Bilingual Lexicography as Recontextualization: A Case Study of Illustrative Examples in a New English-Chinese Dictionary. Australian Journal of Linguistics 35(4): 311-333. 
Chen, Wenge. 2017. Lexicography, Discourse and Power: Uncovering Ideology in the Bilingualization of a Monolingual English Dictionary in China. Pragmatics and Society 8(4): 601-629.

Chen, Wenge. 2019. Towards a Discourse Approach to Critical Lexicography. International Journal of Lexicography 32(3): 362-388.

Cowley, Stephen J. 2011. Distributed Language. Cowley, Stephen J. (Ed.). 2011. Distributed Language: 1-14. Amsterdam/Philadelphia: John Benjamins.

Cronin, Michael. 2017. Eco-Translation: Translation and Ecology in the Age of the Anthropocene. Abingdon/ New York: Routledge.

Dziemianko, Anna. 2020. Smart Advertising and Online Dictionary Usefulness. International Journal of Lexicography 33(4): 377-403.

Ezquerra, Manuel A. 1995. Political Considerations on Spanish Dictionaries. Kachru, Braj B. and Henry Kahane (Eds.). 1995. Cultures, Ideologies and the Dictionary: Studies in Honor of Ladislav Zgusta: 143-152. Tübingen: Max Niemeyer.

Fairclough, Norman. 1992. The Appropriacy of "Appropriateness". Fairclough, Norman (Ed.). 1992. Critical Language Awareness: 33-56. London: Longman.

Farina, Donna M.T.Cr., Marjeta Vrbinc and Alenka Vrbinc. 2019. Problems in Online Dictionary Use for Advanced Slovenian Learners of English. International Journal of Lexicography 32(4): 458-479.

Fellbaum, Christiane. 2014. Large-scale Lexicography in the Digital Age. International Journal of Lexicography 27(4): 378-395.

Fillmore, Charles J. 1985. Frames and the Semantics of Understanding. Quaderni Di Semantica 6(2): 222-254.

Fillmore, Charles J. and Collin F. Baker. 2009. A Frames Approach to Semantic Analyis. Heine, Bernd and Heiko Narrog (Eds.). 2009. The Oxford Handbook of Linguistic Analysis: 313-339. Oxford: Oxford University Press.

Fusari, Sabrina. 2018. Changing Representations of Animals in Canadian English (1920s-2010s). Language \& Ecology: 1-32.

Gibson, James J. 1979. The Ecological Approach to Visual Perception. Boston: Houghton Mifflin.

Godwin-Jones, Robert. 2011. Emerging Technologies: Mobile Apps for Language Learning. Language Learning E Technology 15(2): 2-11.

Gouws, Rufus H. 2014. Article Structures: Moving from Printed to e-Dictionaries. Lexikos 24: 155-177.

Gouws, Rufus H. and Sven Tarp. 2017. Information Overload and Data Overload in Lexicography. International Journal of Lexicography 30(4): 389-415.

Granger, Sylviane. 2012. Electronic Lexicography: From Challenge to Opportunity. Granger, Sylviane and Magali Paquot (Eds.). 2012. Electronic Lexicography: 1-11. Oxford: Oxford University Press.

Halliday, Michael A.K. 1985. An Introduction to Functional Grammar. London: Edward Arnold.

Hodges, Bert H. and Reuben M. Baron. 2007. On Making Social Psychology More Ecological and Ecological Psychology More Social. Ecological Psychology 19(2): 79-84.

Hoey, Michael. 2001. A Clause-Relational Analysis of Selected Dictionary Entries: Contrast and Compatibility in the Definitions of 'Man' and 'Woman'. Caldas-Coulthard, Carmen Rosa and Malcolm Coulthard (Eds.). 2001. Texts and Practices: Readings in Critical Discourse Analysis: 178-190. London: Routledge.

Hornscheidt, Antje. 2008. A Concrete Research Agenda for Critical Lexicographic Research within Critical Discourse Studies: An Investigation into Racism/Colonialism in Monolingual Danish, German, and Swedish Dictionaries. Critical Discourse Studies 5(2): 107-132. 
Hu, Huilian, Hai Xu and Junjie Hao. 2019. An SFL Approach to Gender Ideology in the Sentence Examples in The Contemporary Chinese Dictionary. Lingua 220: 17-30.

Huang, Fang and Sven Tarp. 2021. Dictionaries Integrated into English Learning Apps: Critical Comments and Suggestions for Improvement. Lexikos 31: 68-92.

Huang, Guowen and Ruihua Zhao. 2017. On the Origin, Aims, Principles and Methodology of Eco-Discourse Analysis. Modern Foreign Languages 40(5): 585-596.

Jones, Mari C. (Ed.). 2015. Policy and Planning for Endangered Languages. Cambridge: Cambridge University Press.

Kravchenko, Alexander V. 2009. The Experiential Basis of Speech and Writing as Different Cognitive Domains. Pragmatics \& Cognition 17(3): 527-548.

Kress, Gunther and Theo van Leeuwen. 2006. Reading Images: The Grammar of Visual Design. 2nd edition. London: Routledge.

Lakoff, George. 2010. Why It Matters How We Frame the Environment. Environmental Communication 4(1): 70-81.

Lakoff, George. 2014. Don't Think of an Elephant! Know Your Values and Frame the Debate. 2nd edition. Vermont: Chelsea Green Publishing.

Larsen-Freeman, Diane. 2011. Complex, Dynamic Systems: A New Trandisciplinary Theme for Applied Linguistics? Language Teaching 45(2): 202-214.

Lee, Sang Yong. 2017. A Theoretical Model for a Dictionary of the Endangered Sherpa Language. Unpublished M.A. thesis. Stellenbosch: Stellenbosch University.

Lew, Robert. 2010. Multimodal Lexicography: The Representation of Meaning in Electronic Dictionaries. Lexikos 20: 290-306.

Lew, Robert. 2012. How Can We Make Electronic Dictionaries More Effective? Granger, Sylviane and Magali Paquot (Eds.). 2012. Electronic Lexicography: 343-361. Oxford: Oxford University Press.

Li, Ping. 2012. Ideology-oriented Translations in China: A Reader-Response Study. Perspectives 20(2): 127-137.

Linell, Per. 2009. Rethinking Language, Mind, and World Dialogically: Interactional and Contextual Theories of Human Sense-Making. Charlotte, NC: Information Age Publishing.

Linell, Per. 2013. Distributed Language Theory, with or without Dialogue. Language Sciences 40: 168-173.

Liu, Xiqin. 2015. Multimodal Definition: The Multiplication of Meaning in Electronic Dictionaries. Lexikos 25: 210-232.

Liu, Xiqin. 2017. Multimodal Exemplification: The Expansion of Meaning in Electronic Dictionaries. Lexikos 27: 287-309.

Liu, Xiqin, Dongping Zheng and Yushuai Chen. 2019. Latent Classes of Smartphone Dictionary Users among Chinese EFL Learners: A Mixed-Method Inquiry into Motivation for Mobile Assisted Language Learning. International Journal of Lexicography 32(1): 68-91.

Lyu, Jing and Xiqin Liu. In preparation. For a Better World: Revealing Ecology-destructive Frames in English Learner's Dictionaries.

Makkai, Adam. 1993. Ecolinguistics: Towards a New Paradigm for the Science of Language? London/ New York: Pinter Publishers.

Moon, Rosamund. 2014. Meanings, Ideologies and Learners' Dictionaries. Abel, Andrea, Chiara Vettori and Natascia Ralli (Eds.). 2014. Proceedings of the XVI EURALEX International Congress: The User in Focus, EURALEX 2014, Bolzano/Bozen, Italy, July 15-19, 2014: 85-105. Bolzano/ Bozen: Institute for Specialised Communication and Multilingualism. 
Ogilvie, Sarah. 2013. Words of the World: A Global History of the Oxford English Dictionary. Cambridge: Cambridge University Press.

Rossi, Fabio and Maria Grazia Sindoni. 2017. The Phantoms of the Opera: Toward a Multidimensional Interpretative Framework of Analysis. Sindoni, Maria Grazia, Janina Wildfeuer and Kay L. O'Halloran (Eds.). 2017. Mapping Multimodal Performance Studies: 61-84. New York/ Abingdon: Routledge.

Sarmento, Manoel Soares. 2000. Ecolexicography: Words and Expressions We Should Live By. Österreichische Linguistiktagung Graz, 8.-10. Dezember 2000. Akten des Symposiums 30 Jahre Sprache und Ökologie - Errungenschaften, Visionen. Graz: Graz University.

Sarmento, Manoel Soares. 2002. Ecolexicography: Ecological and Unecological Words and Expressions. Fill, A., H. Penz and W. Trampe (Eds.). 2002. Colourful Green Ideas: Papers from the Conference 30 Years of Language and Ecology (Graz, 2000) and the Symposium Sprache und Ökologie (Passau, 2001): 487-492. Viena: Peter Lang.

Sarmento, Manoel Soares. 2005. Por Uma Ecolexicografia. Confluências 2: 84-97.

Steffensen, Sune Vork. 2015. Distributed Language and Dialogism: Notes on Non-Locality, SenseMaking and Interactivity. Language Sciences 50: 105-119.

Steffensen, Sune Vork and Alwin Fill. 2014. Ecolinguistics: The State of the Art and Future Horizons. Language Sciences 41: 6-25.

Stibbe, Arran. 2014. Ecolinguistics and Erasure: Restoring the Natural World to Consciousness. Hart, Christopher and Piotr Cap (Eds.). 2014. Contemporary Critical Discourse Studies: 583-602. London: Bloomsbury Academic.

Stibbe, Arran. 2015. Ecolinguistics: Language, Ecology and the Stories We Live By. Abingdon/New York: Routledge.

Tarp, Sven. 2007. Lexicography in the Information Age. Lexikos 17: 170-179.

Tenorio, Encarnación Hidalgo. 2000. Gender, Sex and Stereotyping in The Collins Cobuild English Language Dictionary. Australian Journal of Linguistics 20(2): 211-230.

Tian, Yu, Xiao-wei Wang and Xin-qi Guo. 2016. On Ecological Views in Texts of Learner's Dictionaries and Their Educational Functions: A Text Analysis of New Age English-Chinese Dictionary. Journal of Shanxi Datong University (Social Science Edition) 30(6): 73-75, 79.

Trampe, Wilhelm. 2001. Language and Ecological Crisis: Extracts from a Dictionary of Industrial Agriculture (Translated by Peter Mühlhäusler). Fill, Alwin and Peter Mühlhäusler (Eds.). 2001. The Ecolinguistics Reader: Language, Ecology and Environment: 232-240. London/New York: Continuum.

Tsunoda, Tasaku. 2005. Language Endangerment and Language Revitalization. Trends and Linguistics Studies and Monographs 148. Berlin/New York: De Gruyter.

Van Leeuwen, Theo. 2005. Introducing Social Semiotics. London/New York: Routledge.

Van Lier, Leo. 2002. An Ecological-Semiotic Perspective on Language and Linguistics. Kramsch, Claire (Ed.). 2002. Language Acquisition and Language Socialization: Ecological Perspectives: 140-164. London/New York: Continuum.

Wang, Ning. 2003. On the Educational Function of Dictionaries: Comments on New Century Modern Chinese Dictionary by Tongyi Wang. Lexicographical Studies 1: 1-5.

Willinsky, John. 1994. Empire of Words: The Reign of the OED. Princeton, N.J.: Princeton University Press. 
Winestock, Christopher and Young-kuk Jeong. 2014. An Analysis of the Smartphone Dictionary App Market. Lexicography: Journal of ASIALEX 1(1): 109-119.

Wurm, Stephen A. 2007. Threatened Languages in the Western Pacific Area from Taiwan to, and Including, Papua New Guinea. Brenzinger, Matthias (Ed.). 2007. Language Diversity Endangered: 374-390. Berlin/New York: Mouton de Gruyter.

Xu, Hai. 2009. Towards Prototypical Exemplification in English Dictionaries for Chinese EFL Learners. Beijing: Science Press.

Yong, Heming and Jing Peng. 2007. Bilingual Lexicography from a Communicative Perspective. Amsterdam/Philadelphia: John Benjamins.

Zhang, Yihua. 2015. Second Language Acquisition and Learner's Dictionaries. Beijing: The Commercial Press.

Zhang, Yiqiong, David Machin and Tao Song. 2015. Visual Forms of Address in Social Media Discourse: The Case of a Science Communication Website. Journal of Multicultural Discourses 10(2): 236-252.

Zheng, Dongping. 2012. Caring in the Dynamics of Design and Languaging: Exploring Second Language Learning in 3D Virtual Spaces. Language Sciences 34(5): 543-558.

Zheng, Dongping, Kristi Newgarden and Michael F. Young. 2012. Multimodal Analysis of Language Learning in World of Warcraft Play: Languaging as Values-Realizing. ReCALL 24(3): 339-360.

Zhou, Wenjuan. 2017. Ecolinguistics: Towards a New Harmony. Language Sciences 62: 124-138. 
Appendix I: Destructive Instances in "Big Five" Dictionaries

The following definitions and examples are from 30 random pages in each of three English Learner's Dictionaries: OALD9, LDOCE5 and COBUILD8. The coding scheme is as follows.

DictionaryXY: Z where Dictionary $=$ OALD9, or LDOCE5, or COBUILD8; $\mathrm{X}=\mathrm{D}$ (definition) or $\mathrm{E}$ (example); $\mathrm{Y}=$ sense number; $\mathrm{Z}=$ headword. For example, "OALD9E1: bam" means that it is an illustrative example from the first sense of the entry "bam" in Oxford Advanced Learner's Dictionary, 9th edition. For an entry with more than one instance, a number is given in square brackets to indicate the order. For instance, "OALD9E3[1]: abuse" means it is the first instance in this entry.

\section{A. OALD9}

1. OALD9E3[1]: abuse

2. OALD9E3[2]: abuse

3. OALD9E3[3]: abuse

4. OALD9E2: accumulation

5. OALD9E1: bam

6. OALD9E3: bottle

7. OALD9E1: calling

8. OALD9E2: contrast

9. OALD9E2: desertion

10. OALD9E2: dirt

11. OALD9E3: dirt

12. OALD9E2[1]: environment

13. OALD9E2[2]: environment

14. OALD9E6: escape

15. OALD9E8: fly

16. OALD9E1: give up on

17. OALD9E5: graze

18. OALD9D1: hashish

19. OALD9E1: helpless

20. OALD9E1: hurl

21. OALD9E2: hurl

22. OALD9E1: leakage

23. OALD9E1: machine-gun

24. OALD9E4: $\mathrm{mad}$

25. OALD9E1: $\mathrm{mar}$
All the children had been physically and emotionally abused. He had abused his own daughter (= had sex with her).

The boy had been sexually abused.

An accumulation of toxic chemicals.

She pointed the gun at him and — bam!

After his wife died, he really hit the bottle (= started drinking heavily).

He realized that his calling was to preach the gospel.

Her actions and her promises contrasted sharply.

She felt betrayed by her husband's desertion.

He picked up a handful of dirt and threw it at them.

Do you have any dirt on the new guy?

Pollution of the environment.

Damage to the environment.

Toxic waste escaping into the sea.

A large stone came flying in through the window.

His teachers seem to have given up on him.

The bullet grazed his cheek.

A drug made from the resin of the hemp plant, which gives a feeling of being relaxed when it is smoked or chewed. Use of the drug is illegal in many countries.

It's natural to feel helpless against such abuse.

He hurled a brick through the window.

Rival fans hurled abuse at each other.

A leakage of toxic waste into the sea.

A group of prisoners was taken into the forest and machinegunned.

She's completely power-mad.

The game was marred by the behaviour of drunken fans. 

26. OALD9E1: pit
27. OALD9E2: point
28. OALD9E2: rake
29. OALD9E1: raw
30. OALD9D1: rubbish
31. OALD9E1: sea
32. OALD9E1: treatment
33. OALD9E2: which
34. OALD9E4: wretched

\section{B. LDOCE5}
35. LDOCE5D2: amber
36. LDOCE5D1: buckskin
37. LDOCE5E2: clutch
38. LDOCE5E2: coach
39. LDOCE5E1: compromising

40. LDOCE5D2: crocodile

41. LDOCE5E2: crocodile

42. LDOCE5E2: discharge

43. LDOCE5E3: experimentation

44. LDOCE5E11: eye

45. LDOCE5D1: gateway drug
46. LDOCE5E7: go
47. LDOCE5D1: hypnotic
48. LDOCE5E1: hypocrisy

49. LDOCE5E13: job

50. LDOCE5E1[1]: kill

51. LDOCE5E1[2]: kill

52. LDOCE5D1: lanolin

53. LDOCE5E4: lead

54. LDOCE5E1: motivate

55. LDOCE5E26: out

56. LDOCE5D1: pigskin

57. LDOCE5E1: pigskin
The body had been dumped in a pit.

He pointed the gun at her head.

They raked the streets with machine-gun fire.

These fish are often eaten raw.

Things that you throw away because you no longer want or need them.

The waste was dumped in the sea.

Guests at the health spa receive a range of beauty treatments.

Houses which overlook the lake cost more.

Is it that wretched woman again?

\author{
A hard yellowish brown substance used to make jewellery. \\ Strong soft leather made from the skin of a deer or goat. \\ A small boy trying to escape from his mother's clutches. \\ The child was coached for stardom by her mother. \\ The doctor was found in a compromising position with a \\ nurse (= having sex with her). \\ The skin of this animal, used for making things such as \\ shoes. \\ A crocodile briefcase. \\ The discharge of toxic waste into the sea. \\ Experimentation with cannabis. \\ We went to dances, but only under the watchful eye of \\ our father. \\ A drug such as cannabis which is not a very dangerous \\ drug, but which some people believe leads to the use of \\ more dangerous drugs such as heroin. \\ He went crazy and tried to kill her. \\ A drug that helps you to sleep \\ It would be sheer hypocrisy to pray for success, since I've \\ never believed in God. \\ She looks completely different in this photo - she must \\ have had a nose job. \\ Why did she kill her husband? \\ Murray held a gun to his head and threatened to kill him. \\ An oil that is obtained from sheep's wool, and is used in \\ skin creams. \\ What led him to kill his wife? \\ We may never know what motivated him to kill his wife. \\ It's time we voted the Republicans out. \\ Leather made from the skin of a pig. \\ A pigskin suitcase.
}



58. LDOCE5E3: practice
59. LDOCE5E2: raccoon
60. LDOCE5D1: sealskin
61. LDOCE5D1: shammy
62. LDOCE5E1: status symbol
63. LDOCE5E1[1]: staunch
64. LDOCE5E1[2]: staunch
65. LDOCE5E1: stay out
66. LDOCE5E2: unreal
67. LDOCE5E3: well
68. LDOCE5E1: widespread

\section{COBUILD8}

\begin{tabular}{|c|c|}
\hline 69. & COBUILD8E1: admit \\
\hline 70. & COBUILD8E6: aim \\
\hline 71. & COBUILD8E1: air \\
\hline 72. & COBUILD8E1: arrestable \\
\hline 73. & COBUILD8E9: at \\
\hline 74. & COBUILD8E8: chase \\
\hline 75. & COBUILD8E1: chop off \\
\hline 76. & COBUILD8E3: collect \\
\hline 77. & COBUILD8E1: commence \\
\hline 78. & COBUILD8E1: dissect \\
\hline 79. & COBUILD8E2: fright \\
\hline 80. & COBUILD8E1: gore \\
\hline 81. & COBUILD8E2: gossipy \\
\hline 82. & COBUILD8E3: grass \\
\hline 83. & COBUILD8E1: immanent \\
\hline 84. & COBUILD8E4: liberally \\
\hline 85. & COBUILD8E1: move in \\
\hline 86. & COBUILD8E1: pizzazz \\
\hline 87. & COBUILD8E1[1]: prescribe \\
\hline
\end{tabular}

The practice of dumping waste into the sea.

A raccoon coat.

The skin or fur of some types of seal, used for making leather or clothes.

A piece of chamois leather, used for cleaning or polishing.

A Rolls Royce is seen as a status symbol.

A staunch conservative.

One of Bush's staunchest supporters.

He started staying out late, drinking.

Many people go into marriage with unreal expectations.

I went out and got well and truly (= completely) drunk.

The widespread use of chemicals in agriculture.

Up to two thirds of 14 to 16 year olds admit to buying drink illegally ...

He was aiming the rifle at Wade.

... water and air pollutants.

Possession of cannabis will no longer be an arrestable offence.

The crowds became violent and threw petrol bombs at the police...

... bear robes, mountain lion hides, and other trophies of the chase.

They dragged him to the village square and chopped his head off.

After collecting the cash, the kidnapper made his escape down the disused railway line.

The hunter knelt beside the animal carcass and commenced to skin it.

We dissected a frog in biology class.

The snake picked up its head and stuck out its tongue which gave everyone a fright ...

He was gored to death in front of his family.

... gossipy old women.

I started smoking grass when I was about sixteen. (grass = marijuana)

God is immanent in the world.

Chemical products were used liberally over agricultural land.

Her husband had moved in with a younger woman ...

... a young woman with a lot of energy and pizzazz.

She took twice the prescribed dose of sleeping tablets ... 
318 Xiqin Liu, Jing Lyu and Dongping Zheng
88. COBUILD8E1[2]: prescribe
The law allows doctors to prescribe contraception to the under $16 \mathrm{~s}$.
89. COBUILD8E1: repellent
90. COBUILD8E5: sniff
91. COBUILD8E5: sniffer
... a very large, very repellent toad ...
He felt light-headed, as if he'd sniffed glue.
92. COBUILD8E1: struggle on
... teenage glue sniffers.
Why should I struggle on to please my parents? ...
93. COBUILD8E2: salvation ... those whose marriages are beyond salvation.
94. COBUILD8D1: sea
95. COBUILD8E5: trip
96. COBUILD8E7: trip
97. COBUILD8E1: unclean
98. COBUILD8E2: walk out
The sea is the salty water that covers about three-quar- ters of the earth's surface
The biggest star perk, and the biggest power trip, must be the private plane.
One night I was tripping on acid.
... the Western attitude to insects as being dirty and unclean ...
Her husband walked out on her ...
99. COBUILD8E1[1]: weaponize
100. COBUILD8E1[2]: weaponize They were close to weaponizing ricin - a lethal plant toxin.
101. COBUILD8E1: wearer
... the plan to weaponize outer space.
102. COBUILD8E4: $X$
The mascara is suitable for contact lens wearers.
You can only make $\mathrm{X}$ amount of dollars a year. 
Appendix II: Destructive Frames and Ideologies in "Big Five" Dictionaries

See Appendix I for the data source and the coding scheme.

A. Frames of Violence, Drugs and Alcohol: Violence and (Ab)use of Drugs and Alcohol Are Normal

A-1. Frames of Violence: Violence Is Worth a Try; Some Groups of People Are Doomed to Be Hurt or to Be in Conflicts

(1) Sudden Attacks Are Normal Phenomena

- He picked up a handful of dirt and threw it at them. (OALD9E2: dirt)

- A large stone came flying in through the window. (OALD9E8: fly)

- The bullet grazed his cheek. (OALD9E5: graze)

- He hurled a brick through the window. (OALD9E1: hurl)

(2) Public Acts of Violence Are Normal Phenomena

- The crowds became violent and threw petrol bombs at the police ... (COBUILD8E9: at)

(3) People Can Be Killed at Will

- The body had been dumped in a pit. (OALD9E1: pit)

- They raked the streets with machine-gun fire. (OALD9E2: rake)

- A group of prisoners was taken into the forest and machine-gunned. (OALD9E1: machine-gun)

- They dragged him to the village square and chopped his head off. (COBUILD8E1: chop off)

(4) Using Guns Is Cool

- She pointed the gun at him and — bam! (OALD9E1: bam)

- He pointed the gun at her head. (OALD9E2: point)

- He was aiming the rifle at Wade. (COBUILD8E6: aim)

- Murray held a gun to his head and threatened to kill him. (LDOCE5E1[2]: kill)

(5) Married People Are Spouse Killers (Spouse Killing Frame)

- Why did she kill her husband? (LDOCE5E1[1]: kill)

- We may never know what motivated him to kill his wife. (LDOCE5E1: motivate)

- What led him to kill his wife? (LDOCE5E4: lead)

(6) Men and Women Kill Each Other (Gendercide Frame)

- She pointed the gun at him and - bam! (OALD9E1: bam)

- He pointed the gun at her head. (OALD9E2: point)

- He went crazy and tried to kill her. (LDOCE5E7: go)

(7) Children Are the Target of Sexual Harassment

- He had abused his own daughter (= had sex with her). (OALD9E3[2]: abuse)

- The boy had been sexually abused. (OALD9E3[3]: abuse)

- All the children had been physically and emotionally abused. (OALD9E3[1]: abuse)

(8) Due Punishment Can Be Avoided

- After collecting the cash, the kidnapper made his escape down the disused railway line. (COBUILD8E3: collect)

- It's natural to feel helpless against such abuse. (OALD9E1: helpless) 
A-2. Frames of Drugs: Using Drugs Is a Good Experience; People Can Legally Be Drug (Ab)users

(1) Using Drugs Is a Good Experience

- a drug made from the resin of the hemp plant, which gives a feeling of being relaxed when it is smoked or chewed. (OALD9D1: hashish)

- a drug such as cannabis which is not a very dangerous drug, but which some people believe leads to the use of more dangerous drugs such as heroin (LDOCE5D1: gateway drug)

- One night I was tripping on acid. (COBUILD8E7: trip)

- He felt light-headed, as if he'd sniffed glue. (COBUILD8E5: sniff)

(2) People, Including Teenagers, Can Legally Be Drug (Ab)users

- ... teenage glue sniffers. (COBUILD8E5: sniffer)

- I started smoking grass when I was about sixteen. (grass = marijuana) (COBUILD8E3: grass)

- Possession of cannabis will no longer be an arrestable offence. (COBUILD8E1: arrestable)

- experimentation with cannabis (LDOCE5E3: experimentation)

A-3. Frames of Drinking: Drinking Heavily Is a Normal Behavior

- After his wife died, he really hit the bottle (= started drinking heavily). (OALD9E3: bottle)

- He started staying out late, drinking. (LDOCE5E1: stay out)

- I went out and got well and truly (= completely) drunk. (LDOCE5E3: well)

- Up to two thirds of 14 to 16 year olds admit to buying drink illegally ... (COBUILD8E1: admit)

\section{B. Frames of Animals and Plants: Animals and Plants Are Resources for Human (Ab)use}

B-1. Frames of Animals: Animals Are Resources for Human (Ab)use; Animals Are Bad

(1) Animals Can Be Eaten at Will

- These fish are often eaten raw. (OALD9E1: raw)

(2) Animals Can Be Killed at Will

- We dissected a frog in biology class. (COBUILD8E1: dissect)

- ... bear robes, mountain lion hides, and other trophies of the chase. (COBUILD8E8: chase)

- The hunter knelt beside the animal carcass and commenced to skin it. (COBUILD8E1: commence)

(3) Animals Are Raw Materials for Products

- leather made from the skin of a pig (LDOCE5D1: pigskin)

- a pigskin suitcase (LDOCE5E1: pigskin)

- the skin of this animal, used for making things such as shoes (LDOCE5D2: crocodile)

- a crocodile briefcase (LDOCE5E2: crocodile)

- a raccoon coat (LDOCE5E2: raccoon)

- the skin or fur of some types of seal, used for making leather or clothes (LDOCE5D1: sealskin)

- a piece of chamois leather, used for cleaning or polishing (LDOCE5D1: shammy)

- strong soft leather made from the skin of a deer or goat (LDOCE5D1: buckskin)

- an oil that is obtained from sheep's wool, and is used in skin creams (LDOCE5D1: lanolin) 
http://lexikos.journals.ac.za; https://doi.org/10.5788/31-1-1648 (Article)

(4) Animals Are Ugly, Dirty and Dangerous Things

- ... a very large, very repellent toad ... (COBUILD8E1: repellent)

- ... the Western attitude to insects as being dirty and unclean ... (COBUILD8E1: unclean)

- The snake picked up its head and stuck out its tongue which gave everyone a fright ... (COBUILD8E2: fright)

- He was gored to death in front of his family. (COBUILD8E1: gore)

B-2. Frames of Plants: Plants Are Resources for Human (Ab)use

- They were close to weaponizing ricin - a lethal plant toxin. (COBUILD8E1: weaponize) 